November - 2009

\title{
The Impact of Openness on Bridging Educational Digital Divides
}

\author{
Andy Lane \\ The Open University, UK
}

\begin{abstract}
Openness has been a feature of higher education for many decades, particularly through the establishment of open universities, although there remain debates about what openness means in practice. Digital technologies, some based on open principles, and digital content, aided by open licences, have both contributed recently to an extension of what is deemed possible under the heading of openness. Nevertheless, while in principle there may be greater degrees of openness available in higher education it does not mean in practice that many people can still readily avail themselves of these new opportunities to learn, not just because they do not have access to digital technologies but personal circumstances mean they also lack the necessary skills and the confidence to use such technologies in general or for education in particular. In fact it can be argued that this new openness, characterised mainly through the open educational resources movement, may actually widen rather than bridge the digital and educational divides between groups, both within and across national boundaries, through the increasing sophistication in technologies and the competencies expected of learners. This paper reviews some of the evidence supporting these different areas of interest and attempts to provide a synthesis of them. It then argues that actions may be required by many inter-mediaries to help to reduce the diverse social and cultural digital divides within education, including through the mediated use of open educational resources between teachers and learners.
\end{abstract}

Keywords: Open learning; higher education; e-learning

\section{The Origins of Openness in Higher Education}

The discourse around the role of openness in higher education can be said to have seriously started with the inception of the United Kingdom Open University (UKOU) in 1969. While the use of distance teaching methodologies predates this by a century (e.g., the University of London's External degree programme), it was the UKOU that was first named an open university (Tait, 2008). While the choice of the title was a collective one, it was the UKOU's first chancellor, Lord Crowther, who first gave meaning to what openness might mean for the UK Open University (and possibly other open universities) when he said it would be open as to people, places, methods, and ideas in his inaugural speech. This is still reflected in its mission 
(The Open University, 2009), although how these open universities and openness in general is interpreted in practice has changed and is changing further with the advent of open educational resources (OER). This is discussed briefly below and is described in more detail by Gourley and Lane (2009). However the plurality of possible meanings for openness implied in this one institutional case is still reflected today across the wider open and distance learning (ODL) movement (Anderson, 2009), with many attempts to define the essential characteristics of open learning, open schooling, or open education (but rarely it seems open teaching). In many cases, distance teaching universities are found wanting on many aspects of openness as defined by different authors.

While not repeating these debates in this article a notable trend amongst open universities and other universities employing distance teaching methodologies alongside campus-based teaching has been the move away from a discourse based on distance teaching or education to one of open and/or distance learning. In contrast, the principle of open access as a major aspect of openness ('open as to people'), whereby no previous educational qualifications are required before registering on an undergraduate course, and a central feature of the UKOU's operation, is by no means universally adopted by other open universities, despite some having been helped in their own establishment and development by the UKOU. A possible reason for this is that while the ideals of openness in higher education or learning have often been focused around the open universities, the latter have been very much state-led interventions as described in some detail by Tait (2008). Many of these state-led interventions have been intended to fit or not within the prevailing social and higher education systems in their respective countries, often raising particular issues of 'comparability' with campus-based educational institutions.

\section{The New Openness for Higher Education in the $21^{\text {st }}$ Century}

Achieving openness in higher education can be difficult and is not helped by the fact that definitions and names can quickly multiply and become confusing. Open learning, distance learning, supported self-study, informal adult learning, home study, e-learning, lifelong learning and flexi study to name but a few have all been used in different ways to describe certain facets of the act of learning in higher education in the past 40 years. Whereas, as argued above, ideas of openness largely centred on ODL institutions in the late $20^{\text {th }}$ century, since the beginning of the $21^{\text {st }}$ century we have had the rise to prominence across all HE institutions (and beyond) of additional names and ideas to conjure with, such as open content (Wiley \& Gurrell, 2009), open courseware (Carson, 2009), and open educational resources (Casserly \& Smith, 2008; Caswell, Henson, Jensen, \& Wiley 2008), all based upon open licensing (Bissell, 2009) and driven by the emergence and spread of digital technologies. And in contrast to open universities, these open movements have mostly not been state interventions but have arisen through the acts of institutions themselves and wider communities sponsored by philanthropic foundations, although some governments are beginning to take note of these movements (Kumar, 2009).

This diversity of old and new names involving openness reflects the diversity of provision and modes of study that are emerging, and at times debates solely about such names and definitions can become sterile. What is more important is to understand the principles upon which a more 
open educational provision should be based, principles that seem to mainly address a fundamental right of access to education on the part of all, but that also examine the practicalities of providing more open systems, as addressed by many authors in Ilyoshi and Kumar (2008).

\section{The Promise of Open Educational Resources}

A good illustration of the tensions between principles and practicalities is shown by open educational resources (the most widely used term for the openly licensed content and tools being used specifically for educational purposes).

Openness, when looked at in terms of OER, is centrally concerned with freedoms as expressed in the open licences applied to them:

- freedom from paying any money to access and use the content for specified purposes,

- freedom to copy and make many more copies,

- freedom to take away and re-use without asking prior permission,

- freedom to make derivative works (but not necessarily freedom to make profits from them).

So, openness can be equated with freedoms, but the degrees of freedom available within a particular openness can vary (as seen in the spectrum of Creative Commons licences themselves) and can be influenced by many other factors beyond the licence and particularly how potential users perceive their openness. For example, the UKOU's work with the BBC has meant that educational radio and TV programmes associated initially with courses have been openly available (free to view at first then free to record when technology allowed) through terrestrial public service broadcasting in the UK ever since the Open University began teaching in 1971. Thus, people have had the freedom to access and to copy this particular copyrighted content using video recorders for personal use but not the freedom to use what they record for educational or public performance purposes without a licence or prior permission.

In attempting to cover both principles and implications for practicalities, Schaffert and Geser (2007) have set out four dimensions of openness for OER, which are heavily influenced by digital technologies and where they feel that all dimensions need to be present for maximum openness (Figure 1). For example, a document written with MicroSoft Word ${ }^{\mathrm{TM}}$ can easily be shared, copied, and altered if it has an open licence but it does mean that you as the author and others reusing it have to have purchased proprietary software to do so. It is still early in the OER movement, but the evidence to date points to a change in the dynamics of adult learning, between teachers and learners and between formal higher education and informal adult learning, as this new range of openness becomes more widespread (McAndrew et al., 2009). What is almost certain is that there are now more educational resources potentially available to many more people than there have ever been before.

Figure 1 illustrates the meaning of 'open' in open educational resources (Schaffert and Geser, 2008). 


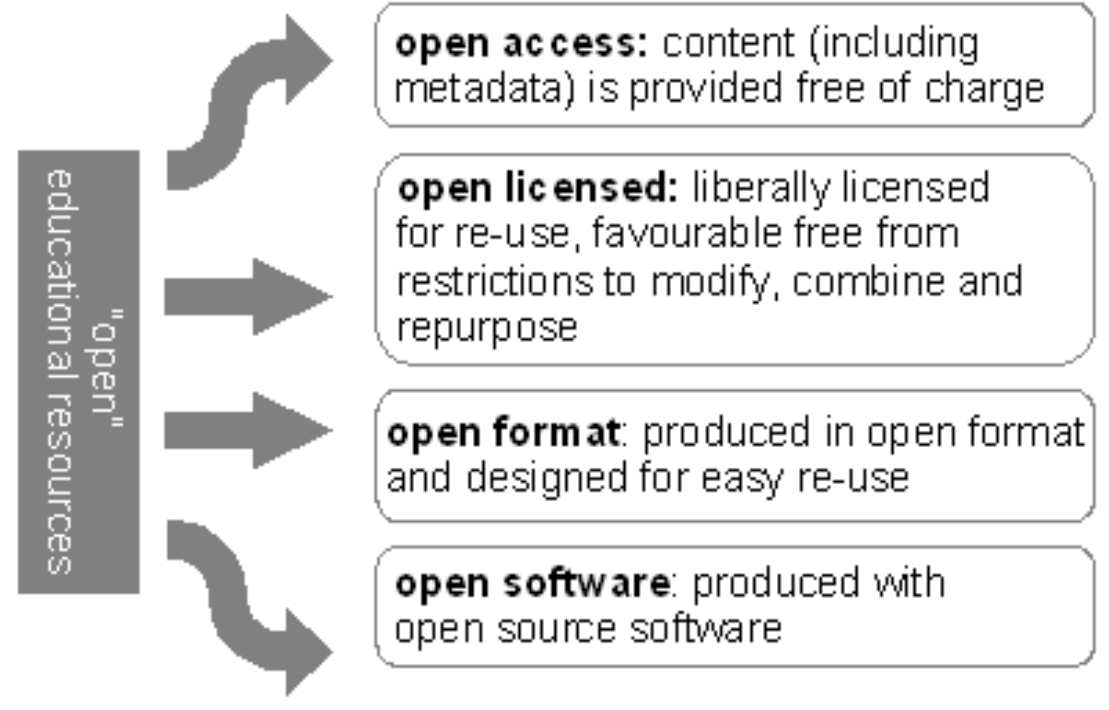

Figure 1. The meaning of open in open educational resources.

\section{The Impact of Digital Technologies}

This brief review of openness suggests that digital technologies, in the form of open content, open licences, open formats, and open software, are expanding the potential for addressing some of the barriers to education. And yet there is still considerable concern over a growing digital divide in terms of the availability and accessibility of the digital devices for using these developments for educational purposes.

The advent of digital technologies and their use within e-learning schemes has also opened up further possibilities for open learning by increasing the scope for much more non face-to-face, two-way interaction and collaboration between groups of learners and their teachers. At the same time the availability, affordability, accessibility, and acceptability of this mode of teaching and learning is extremely variable, with socially excluded groups or communities being those who do not have much access to such technologies, who may find few opportunities available to them in their circumstances, and who are worried that they cannot cope with these new technologies and ways of learning. In other words they do not feel included even when people are trying to reach out to them because they lack confidence in their competence to succeed - they feel disempowered.

Open educational resources on their own offer little respite to the barriers noted above. Yes, in principle, they are cost-free to the learner and do not require any prior qualifications. They may enable some to study materials on their own without any social or cultural pressures. But they often require computers and Internet access unless someone can produce low or no-cost hard copies instead, a problem that is often exacerbated in rural/remote locations. 


\section{Educational Divides and Excluded Communities}

Before talking further about the role of digital technologies and the educational digital divide it is important to acknowledge the significant educational divide that already exists, especially for higher education. Certain societal groups or communities may be excluded from current educational provision for a variety of reasons. Within higher education some or all of the following may be barriers to particular groups and communities engaging with available provision (Lane, 2008a):

- Geographical remoteness, even in rural areas of small countries;

- Cultural norms, with some ethnic cultures not supporting the education of women in particular circumstances, for instance (Khokhar, 2008);

- Social norms, whereby some family groups or communities do not value education as highly as others, so discouraging engagement;

- Prior achievements, such as prior qualifications being used as a filter related to accessing a scarce resource or to maintaining an individual institution's social and cultural status;

- Individual or household income, where the relative cost of accessing higher education by certain groups is very high;

- Digital divide, in that although computers and the Web offer many freedoms, they still cost money to access, and people with less money may not easily afford such technology and may even find that the absolute cost to them is higher than to other groups because they are seen as a greater financial risk to a technology provider;

- Physical circumstances, whereby there may not be any easy places to undertake the learning due to lack of a home, space in a home, or having a particular type of home, such as a prison, and similarly, people with certain disabilities may need specialist equipment or support (Cooper, Lowe, \& Taylor, 2008);

- Individual norms, where a person is constrained by social and cultural norms - attitudes and beliefs - that they are not capable or not good enough to study at this level, as may be the case with older people (Martin, 2009).

This is a formidable set of barriers, with possibly the last one being crucial as without the intent to learn at this level, the other barriers may be perceived rather than real. Indeed, Norris (2001) argued that the use of new technology can be understood as the product of resources (time and money), motivation (interest and confidence) and the structure of opportunities (such as social, cultural, and political networks). Many studies have investigated the complexity of how different groups in particular societies may use digital technologies (e.g., Van Dijk \& Hacker, 2003), and it does not take much to imagine the plight of migrant or displaced people who may have to cope with different systems of provision, different expectations, and a different language to that of their home country. 


\section{Digital Skills, Digital Contexts, and the Digital Divide}

Much of the digital divide debate concerns the fact that some groups or people in societies have differing access to new digital technologies, which is in effect an economic divide created by relative purchasing power. However, many have raised the issues of usability of the digital technologies and empowerment being other socially dividing factors (Norris, 2001; Van Dijk \& Hacker, 2003; Nielsen, 2006), and others have looked at this specifically for education (Enoch \& Soker, 2006).

The economic divide has mainly focused on access to personal computers, whether desktop or laptop machines. But with greater types of digital devices (particularly mobile devices) becoming available, with more computing power and accessibility to communication networks, and with the ever declining cost of computing and communication services, this is probably not the most pressing long-term issue for the educational divide. The growing availability, affordability, and accessibility of digital devices that can be used for educational purposes means that teachers can plan more confidently knowing that their students will not be so greatly disadvantaged and in some cases certain groups, such as the visually impaired, may be better served than with nondigital technologies (Cooper, Lowe, \& Taylor, 2008).

The usability divide or usage gap refers to the technology being too complicated to use or requiring sophisticated skills and competencies to use for particular purposes. In other words, how adept are people at using the technology and conversely how simple has the technology been made to use by those creating it? This issue is often discussed through the topic of digital literacy (or fluency). The most quoted definition of digital literacy is that of Gilster (1997): “... the ability to understand and use information in multiple formats from a wide range of sources when it is presented via computers."

But as noted in Newrly and Veugelers (2009), Stayaert has expanded this to encompass instrumental skills (simple actions to control features and programmes on the digital device), structural skills (dealing with information being managed using the features and programmes), and strategic skills (applying the instrumental and structural skills in creative and reflective ways). A similar focus on skills within digital literacy is seen in this definition from Martin (2006):

Digital literacy is the awareness, attitude and ability of individuals to appropriately use digital tools and facilities to identify, access, manage, integrate, evaluate, analyse and synthesise digital resources, construct new knowledge, create media expressions, and communicate with others in the context of specific life situations, in order to enable constructive social action, and to reflect upon this process.

Much of this discussion about digital literacy revolves mainly around a modern day skill set that relies on digital technologies or tools, but does not specify the full nature of these skills nor their 
role in relation to educational literacy or learning how to learn (Selwyn \& Facer, 2007). To simplify, both self-communication (learning) and person(s) to person(s) communication involves the manipulation of words, numbers, sounds, 'symbols and pictures' mediated by the technologies being used (or not) as aids to the process. Words can be as speech or written text, and the skill of understanding (aka listening/reading) or manipulating them (speaking/writing) are known as articulacy and literacy. Similarly, symbols and pictures, static or dynamic, involve a skill set known as graphicacy.

Putting aside this terminology for a moment, the general issues around these skills are with being able to be a participant in society. It is being able to participate in everyday life and work either because you can understand/interpret/enjoy the communicative outputs of others and/or because you can make your own outputs that others can understand/interpret/enjoy. The most interesting developments for education are how technology defines and/or shapes which mode of ***acy is used and who is able to use it (effectively). Digital technologies are changing the ability to produce and share graphical representations such that they are becoming a serious area of research and activity (despite the practice being hampered by no agreed grammar for such outputs). Similarly, video use has been even more influenced by digital technology so that the skills of producing and interpreting such outputs are more widespread and more familiar than ever. The argument being made is that digital technologies are not only changing the medium and practice of communication but also the predominant form of expression within that medium. If so, how competent do we all need to be in these different ***acies and in the technologies that enable us to participate (if we want to) in that particular form of communication and collaboration? Such questions apply as much to teachers as to learners since both need to be equally comfortable with the technology and the practices it supports.

As noted previously, the advent of digital technologies and their use within e-learning or blended learning schemes has opened up further possibilities for open learning by increasing the scope for more non face-to-face, two-way interaction and for forms of collaboration between groups of learners and their teachers. At the same time the availability (physical access), accessibility (usability), and acceptability (social empowerment) of this mode of teaching and learning is extremely variable. Socially excluded groups or communities, who do not have much access to such technologies, may find few opportunities available to them in their circumstances and may worry that they cannot cope with these new technologies and ways of learning (Kirkwood, 2006a; 2006b). To reiterate, they do not feel included even when people are trying to reach out to them because they lack confidence in their competence to succeed.

This disempowerment can be viewed as excluded communities having few, if any, degrees of freedom to engage with open learning. The contrast here is between the discourse and practice of making educational materials, activities, and opportunities as open as possible by certain groups in societies and with the freedoms that are embodied within the different types of openness. One example is the practice of open access to undergraduate courses where no prior qualifications are needed to register - that is students have freedom from discrimination on the basis of prior achievement. However open access does not mean that the course is free of cost or that there are no constraints to the freedom of when the course can be studied and assignments submitted. 
Another example is open educational resources where there is much greater freedom around cost (they are free to access although there may be costs to being online) and time of study (they can be studied at any time as long as they are available and accessible by the user, i.e., they can get online). These freedoms are made more possible with digital resources as they can be accessed simultaneously by many people and infinitely replicated. As noted earlier, both the relative abundance of and non-destructive through consumption attributes of a digital resource means that issues of physical scarcity no longer apply.

\section{The Inter-Mediation of Teaching and Learning}

Formal education is a structured set of activities where a key element is the interactions between teachers and learners and between fellow learners, interactions that are supported by educational content (e.g. textbooks, course notes, assignments) and learning resources (e.g. whiteboards, laboratory equipment, virtual learning environments). In this triangular relationship between teachers, learners, and resources, it is mainly teachers that select and/or develop the set of resources and activities that learners are expected to engage with. As argued by Lane (2008b), teachers attempt to mediate the interactions between the students and the resources (or intermediate), acting as an expert and/or a guide to the learning process. Of course this simple model ignores the wider and variable social and cultural settings for these activities, e.g., the other people who can be a part of the educational relationship, such as librarians, mentors in workbased settings, and technical support staff. Nevertheless, such inter-mediation in structured settings is dominated by a largely closed, face-to-face presence model rather than an open and distance mode, but it is still a feature of ODL systems. Openness rarely extends to offering completely unfettered choices to the learners on what to study, when, how, and where; although, there are some emerging community-based operations on the Web, such as Wikiversity and the Peer-to-Peer University (Thierstein, Schmidt, \& Håklev, 2009).

Under this view of education, if learners are to effectively engage with formal educational opportunities then that process is normally mediated by the structuring of the educational resource by teachers, the learners' own capabilities, the inputs of fellow learners, and the interventions of professional teachers/support workers (Lane, McAndrew, \& Santos, 2009; McAndrew et al., 2009). Openness, in the form of OER, may impact on not only this formal education but also much informal education. Firstly, digital resources and digital environments can substitute for physical resources and physical environments, but inevitably they are different and the need to learn and understand how to create, navigate, and use such resources must not be underestimated. The digital educational divide can mean that some learners are much more sophisticated users of digital technology for learning than their (subject-focussed) teachers, while such fluency (or not) with the technology can exacerbate the educational divide as modes of communication, collaboration, and computation multiply or become more sophisticated. Secondly, the very openness of an OER means that learners have much more access to structured content without the other structuring provided by intermediaries such as teachers. While such wide and free access may be good in principle, in practice it may be difficult for less sophisticated learners to make good use of them without direct support from intermediaries. 
So, while openness within education and the use of open educational resources have the potential to reduce inequalities in the educational divide, the already existing digital divide may be exacerbated. In particular, the availability, accessibility, and acceptability of this mode of teaching and learning is extremely variable, with socially excluded groups or communities being those who do not have much access to such technologies, who may find few opportunities available to them in their circumstances, and who are worried that they cannot cope with these new technologies and ways of learning. In other words, it is the social and cultural factors that may be more important than the economic ones. In such cases of disempowerment, there must be appropriate social and cultural support for the prospective learner to help reduce or remove these disempowering conditions. As Wilson (2008), Selwyn, and Facer (2007) and McAndrew et al. (2009) argue, interventions need to recognise and draw upon existing networks within communities, using local champions to develop skills and confidence, and allow people to make an informed choice about their learning and their use of digital technologies for that learning.

\section{Conclusions}

Divisions between people arise through a combination of many factors - social, cultural, geographical, attitudinal, political, and economic. Digital divides and educational divides are no different. In terms of the educational digital divide, this article has argued that it is the teachers' and the learners' contexts, their motivations and fluency in digital and educational skills, and the support provided by intermediaries that matter most in bridging the gaps. Openness as a philosophy is also important but something being freely available (e.g., open access, open educational resources, etc.) is insufficient to enable many people to successfully engage with a more open educational provision. This article has also argued that it is how that openness is instantiated or structured to meet the particular needs of excluded groups that makes the difference, with mediation between the various actors in the teachers' and learners' contexts (that is third parties who support either or both) being a necessary element. 


\section{References}

Anderson, T. (2009, January 15). On open, distance, e-learning and other name confusion [Web $\log$ post]. Retrieved from http://terrya.edublogs.org/2009/01/15/on-open-distance-elearning-and-other-name-confusion/.

Bissell, A. N. (2009). Permission granted: Open licensing for educational resources. Open Learning: The Journal of Open and Distance Learning, 24(1), 97-106.

Carson, S. (2009). The unwalled garden: Growth of the OpenCourseWare Consortium, 20012009. Open Learning: The Journal of Open and Distance Learning, 24(1), 23-29.

Casserly, C., \& Smith, M. (2008). Revolutionising education through innovation: Can openness transform teaching and Learning? In T. Ilyoshi \& M.S. Vijay Kumar (Eds.), Opening up education: The collective advancement of education through open technology, open content, and open knowledge (pp. 261-276). Cambridge, MA: MIT Press.

Caswell, T., Henson, S., Jensen, M., \& Wiley, D. (2008). Open educational resources: Enabling universal education. The International Review of Research in Open and Distance Learning, 9(1). Retrieved from http://www.irrodl.org/index.php/irrodl.

Cooper, M., Lowe, T., \& Taylor, M. (2008). Access to mathematics in web resources for people with a visual impairment: Considerations and developments in an open and distance learning context. In K. Miesenbergeret et al. (Eds.), ICCHP 2008, LNCS 5105 (pp. 926933). Berlin: Germany: Springer-Verlag.

Enoch, Y., \& Soker, Z. (2008). Age, gender, ethnicity and the digital divide: University students' use of web-based instruction. Open Learning: The Journal of Open and Distance Learning, 21(2), 99-110.

Gilster, P. (1997). Digital literacy. New York: John Wiley.

Gourley, B., \& Lane, A. (2009). Re-invigorating openness at The Open University: The role of open educational resources. Open Learning: The Journal of Open and Distance Learning, 24(1), 57-65

Huijser, H., Bedford, T., \& Bull, D (2008). OpenCourseWare, global access and the right to education: Real access or marketing ploy. The International Review of Research in Open and Distance Learning, 9(1). Retrieved from http://www.irrodl.org/index.php/irrodl.

Ilyoshi, T., \& Vijay Kumar, M.S. (2008). Opening up education: The collective advancement of education through open technology, open content, and open knowledge. Cambridge, MA: MIT Press. 
Khokhar, B. (2007, September). Widening Participation: How can new technologies best be used to enhance learning and teaching and ensure educational inclusion and engagement for excluded groups? Paper presented at the $12^{\text {th }}$ Cambridge International Conference on Open and Distance Learning, Cambridge, UK. Retrieved from http://www2.open.ac.uk/r06/conference/.

Kirkwood, A. (2006a). Getting networked learning in context: are on-line students' technical and information literacy skills adequate and appropriate? Learning, Media and Technology, 31(2), 117-131.

Kirkwood, A. (2006b). Going outside the box: Skills development, cultural change and the use of on-line resources. Computers \& Education, 47, 316-331.

Kumar, M.S. V. (2009). Open educational resources in India's national development. Open Learning: The Journal of Open and Distance Learning, 24(1), 77-84.

Lane, A.B. (2008a). Am I good enough? The mediated use of open educational resources to empower learners in excluded communities. Proceedings of $5^{\text {th }}$ Pan Commonwealth Forum on Open and Distance Learning. Retrieved from http://www.wikieducator.org/PCF5/Governance_and_social_justice.

Lane, A.B. (2008b). Who puts the education into open educational content? In R. N. Katz, (Ed.), The tower and the cloud: Higher education and information technology revisited (pp. 158-168). Boulder, Colorado: Educause.

Lane A.B., McAndrew, P., \& Santos, A. (2009). The networking effects of OER.

Proceedings of ICDE 2009 Conference. Retrieved from http://www.ou.nl/Docs/Campagnes/ICDE2009/Papers/Final_Paper_279Lane.pdf.

Martin, A. (2009). Digital literacy for the third age: Sustaining identity in an uncertain world.

eLearning $\quad$ Papers, $12 . \quad$ Retrieved from http://www.elearningpapers.eu/index.php?page=doc\&doc_id=13518\&doclng=6\&vol=12.

McAndrew, P., Santos, A., Lane, A., Godwin. P., Okada, A., Wilson, T., Connolly, T., Ferreira, G., Buckingham-Shum, S., Bretts, J., \& Webb, R. (2009). OpenLearn research report (2006-2008). Retrieved from The Open University website: http://oro.open.ac.uk/17513/.

Nielsen, J. (2006). Digital divide: The three stages. Retrieved from http://www.useit.com/alertbox/digital-divide.html.

Norris, P. (2001) Digital divide: Civic engagement, information poverty and the internet worldwide. Cambridge, UK : Cambridge University Press.

Schaffert, S., \& Geser, G. (2008). Open educational resources and practices. eLearning Papers, 
http://www.elearningpapers.eu/index.php?page=doc\&doc_id=11198\&doclng=6\&vol=7.

Selwyn, N., \& Facer, K. (2007). Beyond the digital divide - Rethinking digital inclusion for the 21st century. Retrieved from Futurelab website: http://www.futurelab.org.uk/resources/documents/opening_education/Digital_Divide.pdf.

Tait, A. (2008). What are open universities for? Open Learning: The Journal of Open and Distance Learning, 23(2), 85-93.

The Open University (2009). About the OU: Our mission. Retrieved from http://www.open.ac.uk/about/ou/p2.shtml.

Thierstein, J., Schmodt, P., \& Håklev, S. (2009, August). P2P University: Beginning the journey. Paper presented at the OpenEd 2009 Conference, Vancouver, Canada. Retrieved from http://openedconference.org/archives/414.

Van Dijk, J., \& Hacker, K. (2003). The digital divide as a complex and dynamic phenomenon. The Information Society, 19(4), 315-326.

Veugelers, M., \& Newrly, P. (2009). How to strengthen digital literacy? Practical examples of a European initiative "SpreaD." eLearning Papers, 12. Retrieved from http://www.elearningpapers.eu/index.php?page=doc\&doc_id=13522\&doclng=6\&vol=12.

Wiley, D., \& Gurrell, S. (2009). A decade of development. Open Learning: The Journal of Open and Distance Learning, 24(1), 11-21.

Wilson, T, (2008). New ways of mediating learning: Investigating the implications of adopting open educational resources for tertiary education at an institution in the United Kingdom as compared to one in South Africa. The International Review of Research in Open and Distance Learning, 9(1). Retrieved from http://www.irrodl.org/index.php/irrodl. 